\title{
THE CORRELATION BETWEEN STUDENTS' WRITING ABILITY AND THEIR VOCABULARY MASTERY
}

\author{
Dzur Rif'ah Mahmudah \\ English Education Department, Faculty of Teacher Training and Education \\ Muhammadiyah University of Makassar \\ dzur.rifahmahmuda@unismuh.ac.id.
}

\begin{abstract}
This research aimed to find out the correlation between students' writing ability and their vocabulary mastery of the eighth grade students SMP Handayani Sungguminasa Gowa. The problem statement of the research was, "is there any correlation between students' writing ability and their vocabulary mastery?" The research used a Descriptive Research, the instrument of this study was test, namely writing ability (in terms of rewriting of the story in film) test, and vocabulary mastery test. The population of this research is at the eighth grade students of SMP Handayani Sungguminasa Gowa which consist of 28 students, all of them were the sample. Therefore, this research used cluster sampling. The result of the data analysis shows that the students' writing ability (in terms of rewriting of the story in film) stated in 60.00 of the mean score, where their vocabulary mastery test stated 61.00 of the mean score. Coefficient correlation between both variables shows that there is a significant correlation between students writing ability and their vocabulary mastery, it has lies between 0,600 - 0,800 which is categorized as substantial.
\end{abstract}

Keywords: correlation, writing, vocabulary, ability

\section{INTRODUCTION}

English covers four skills namely speaking, reading, listening and writing. There are also three parts in language such as vocabulary, grammar, and pronunciation should be learnt. Those parts play important role supporting the skills of language in use. In Indonesia English language is very important to learn in improving knowledge, technology, and culture by using English.

Writing is one of communication skills as means of communication that we must consciously learn because no one learns to write automatically. People cannot write even a single letter of the alphabet without a conscious effort of mind and hand, and to get beyond the single letter we must be shown how to form words, how to put shown together into sentences, and how to punctuate those sentences.

Vocabulary is very important in order to understand English. Nunan, citied in Surniati (2006) stated that one of important parts in the acquisition of the 
second language is the development of a rich vocabulary. Jung (citied in Setiawandi, 2006) also stated that 'the researchers and learners have recognized vocabulary use and development as a major aspect of learning new language. The amount of vocabulary is also affecting the understanding of communication.

Vocabulary is one important aspect in learning a foreign language. With a limited vocabulary anyone will also has a limited understanding in terms of speaking, reading, listening, and writing. It is true that it might be impossible to learn a language without mastering vocabulary. Vocabulary is one of the problems confronted by English language learners. Because of the limited vocabulary, the learners cannot communicate to others clearly. Sometimes it is difficult to group the idea transmitted to them. The acquisition of a large number of vocabularies can help the students read, speak, listen, and write. A good vocabulary and ability to use words correctly and effectively can help the students make school work easier and more rewarding, and also many tests that they take in school include vocabulary questions. The more vocabularies they know the better their chance to do well on an English test.

Based on the observation I have did in the school at SMP Handayani Sungguminasa Gowa, actually there were many aspect that make the students develop their vocabulary, they are still lack of vocabulary. The students' needs a particular media to improve their vocabulary.

By Knowing about students' vocabulary of SMP Handayani sugguminasa The writer tries using Audio visual material for teaching vocabulary, Movie is one of audiovisual material that teacher can use as media for teaching English. Movie can caught the students attention for learning vocabulary. Film as a media of teaching vocabulary it affective for make the students easy understand.

Film is one of the audiovisual media in learning English. Bazalgette, C (1989) cited in Watson stated that television, film, radio, telegraph, video, popular music, printed materials and computer software can increase children's critical understanding. In order to build critical understanding, students should understand the language in film. However, in Indonesia, film is still not widely used as tool in learning English in public schools. Geddes and Sturtridge (1982) noted that 
student's visual and critical awareness would increase through watching film activity. Through watching film, students are expected to understand what happened in film and try to retell the story in the film. It's mean that the student's rewriting of the story in the film deals with student's vocabulary mastery.

Subtitle is a tool to help the students understand of the language used in the film. It also can be a media in learning vocabulary. A research conducted by patricia S Konskinen and friends revealed that television program with subtitle could help the students improve their vocabulary acquisition.

\section{THE CONCEPT OF VOCABULARY MASTERY}

\section{a. Definition of Vocabulary}

Norbert Schmitt in Setiawandi (2006:5) states that vocabulary is a basis of a language, it is very important to be master first. We cannot speak well and understand written material if we do not master it. Norbert Schmitt stated that no matter how successfully the sound of the foreign language is mastered, without words to express the wider range of meanings, communication of foreign language just cannot happen in meaningful way.

According David Crystal (1995:116) vocabulary is the Everest of language for this reason; a person who wants be able to communicate in certain language has to master the vocabulary of the language for the first time. Vocabulary as one of the language aspects have to be learned when people are learning a language. Good mastery of vocabulary is important for anyone who learns the language used in listening, speaking, writing, and reading besides grammar. A learner of the foreign language will speak fluently and accurately, write easily, or understand what he or she reads or hears if he or she has enough.

According to Richards, Vocabulary is one of the most obvious components of language and one of the first things applied linguist turned their attention to. Langan states that a good vocabulary it a vital part of effective communication. A command of many words will make you better writer, speaker, reader and listener. Studies showed that students with strong vocabularies or students who work to improve a limited vocabulary are successful in school. 
Alexander, in fluency in English pointed the definition of vocabulary is the ability to deduce the meaning of words and phrase from a context and to explain there by other words and phrases. McCarthy also says that English vocabulary has a remarkable range, flexibility and adaptability.

Based on Longman Dictionary of English and Culture (19998:1177) said the vocabulary is a list of words usually in alphabetic order and with explanation of their meanings less complete than dictionary. From Oxford Dictionary said that vocabulary is a list of words with their meaning especially in a book for learning a foreign language.

So we can conclude that vocabulary is all the words that used in language and each has meaning each of it. Also consist of some parts like verbs, idioms, adverb, pronunciation and etc. learning vocabulary was very important before we learn four basic skills in the language.

b. The importance of Vocabulary

Students' vocabulary which is arranged into sentences to express their opinion, thought and idea. They use it in social communication. The other importance of vocabulary is suggested a follows:

"Vocabulary is important to students, it is more important than grammar for communication purposes, particularly in the early stages when students are motivated to learn the basic words they need to get in language. Also, as the lexical system is 'open', there is always something new to learn when students have 'done' the grammar. So more advanced students are motivated to add to their vocabulary stock, to understand nuances of meaning, to become more proficient in their own choice of words and expressions."

The mastery of vocabulary is very important. We use vocabulary in the form language to express our feelings, idea, etc. whether is orally or in written to other people. Gains and Redman (1986:49) talking about vocabulary, it cannot be separated from four language skills: listening, speaking, reading, and writing. The proficiency of someone's speaking is influenced by his/her vocabulary. To clarify that, let us look at the importance of vocabulary relating to the language skills. 
In listening, vocabulary is used to understand someone's speech or what someone says. It is very hard for us to catch what someone says if we just know the construction of sentence without knowing the words.

In speaking, vocabulary is used to express our ideas or feelings to the others orally. The words that we have influence how effective the communication runs. In reading it is used to comprehend the reading material. Reading without vocabulary mastery will cause difficulties in comprehending a text. The number of words, which someone knows will affect his/her reading activity. It is impossible to understand passage unless he/she knows the meaning of words used in passage.

In writing, the writer use vocabulary to develop his/her idea, a writer should choose the words clearly and accurately to express his/her ideas. Without knowing much vocabulary, we cannot develop our writing because we are limited on vocabulary mastery.

Vocabulary mastery is very important in English language learning. There are many ways that teacher can do to teach vocabulary mastery. One of them by showing visual and verbal cues as well to get the students recall on the vocabulary easily. The presence of both pictorial and verbal cues can facilitate learning, in particular when the corresponding visual and verbal representation are contiguously present in working memory (Mayer, 1997, 2001 2002;Wittrock.1989,in Linda 2004)

In this research the students' vocabulary mastery is tested using film with subtitles as the media in learning English. Terrel (2001 in Linda 2004) found that combining and unknown 1.2 words with a visual representation bypasses a direct translation and facilitates vocabulary learning. Other research suggest that foreign words associated with aural or written translation and image and learned more easily than are those accompany ed by pictures or text alone (Baltova 2000;)its means that visual representation shown on pictures in film and also the translation. Shown in the subtitle can help the students easier in getting the vocabulary meaning. 


\section{c. Types of Vocabulary}

According to Armbruster, Lehr and Osborn (2001:1) sates that Vocabulary refers to the words we must know to communicate effectively vocabulary can be describe as oral vocabulary or reading vocabulary. Oral vocabulary refers to words that use in speaking or recognize in listening. Reading vocabulary refers to words we recognize or use in print.

Furthermore, Armbruster, Lehr and Osborn, (2001) classifies vocabulary into four types, they are:

a) Listening Vocabulary

A person's listening vocabulary is all the words he or she can recognize when listening to speech. This vocabulary is aided in size by context and tone of voice.

b) Speaking vocabulary

A persons' speaking vocabulary is all the words he or she can use speech. Due to the spontaneous nature of the speaking vocabulary, words often misused. This misused though slight and intentional may be compensated by facial expressions, tone and voice, or hand gestures.

c) Reading vocabulary

A person's reading vocabulary is all the words he or she can recognize when reading. This is the type of vocabulary simply because it includes the other three.

d) Writing vocabulary

A person's writing is all the words e or she can employ in writing. Contrary to the previous two vocabulary types, the writing vocabulary is stimulated by its user.

e) Focal vocabulary

"Focal vocabulary" is a specialized set of terms and distinctions that is particularly important for a certain group; those with particular focus of experience or activity, a lexion, or vocabulary, is a language dictionary, its set of names for things, events, and ideas. Some linguists believe that lexicon influences people's perception on thongs. 
According to Raja T. Nasr, there are two kinds of vocabulary:

a. Productive vocabulary (sometimes called active vocabulary): the words that a speaker actually uses.

b. Receptive vocabulary (sometimes called passive vocabulary): words that people understand when he hears or reads them but does not use in his own speech.

Jo Ann Aebersold and Mary Lee field classify into active and passive.

1. Active vocabulary refers to put item which learner can use appropriately in speaking or writing, and it is also called as productive vocabulary, although in fact it is more difficult to put into practice, it means that to use the productive vocabulary, the students must know how the pronounce it well, they must familiar with collocation and understand the connotation meaning of the words. This type is often used in speaking and writing skills.

2. Passive vocabulary refers to language items can be recognize and understand in the context of reading or listening and also called as receptive vocabulary.

Meanwhile Djlinushah and Alimar Enong divide vocabulary into two, namely general vocabulary and special vocabulary. General vocabulary is the words that are use in general. There is no limit $\mathrm{f}$ field and user. Whereas special vocabulary is that the words are used in the certain field and job, profession of special science and technology.

d. The Factor Influence Vocabulary

According to Gower, there are seven factors influence the vocabulary items is easy or difficult to mastery. They are similarity to L1, similarity to English words already known, connotation, spelling and pronunciation, multiwords item, collocation, and appropriate use. The explanation as follows:

1) Similarity to L1

The difficulty of a vocabulary item often depends on how similar the items are in form and meaning to the students' first language.

2) Similarity to English words already known 
Students have some English then a word which is related to an English word they are already familiar with is easier than one which is not.

3) Connotation

Learners have to grips with is the connotation of word.

4) Spelling and pronunciation

The spelling of many English words can cause the problems for students who speak languages with very regular system. Particularly patterns can also cause confuse where the pronunciation is concerned.

5) Multi-word items

A lexical item may consist of more than one word, as in compound noun or phrasal verb.

6) Collocation

The way some grammatical structures are formed depends on knowing which words go with others and which do not. Linda also states that knowing syntactic behavior associated with the word and also knowing the network of associations between that word and other words in the language.

7) Appropriate

Gower points some words and expressions are restricted to use in particular context also it is important that students know whether the words or phrase has a marked style-informal or formal. Students have to take care with the use of colloquial and slang expressions.

\section{The Concept of Film}

Film is term that encompasses individual motion pictures, the field of film as an art form, and the motion picture industry. Film are produced by recording images from the world with cameras, or by creating images using animation techniques or special. In language learning, film is one of audiovisual material in a form of video.

According to Stempleski \& Tomalin (1990:3) the interest of children and adults will occur quicken when the language is experience in a lively way through television and video. The help of moving picture and sound builds the interest. In addition, the 
videos can also help the students to develop their skills in learning English such as listening, speaking, reading and writing skills. Giving certain activities by using video materials can develop the four skills.

Film can be one of audiovisual material to learn English better since there are combination of sounds and picture on it. Audiovisual media are closer to real life because visual clues and context make it possible 'view' the message as much listen to it (Baltova, 1994: 508, cited in Danan 2004).

In this research the use of film as audiovisual material is to measure students' rewriting of the story in the film. Another important thing in rewriting the story in film is the vocabulary mastery of the students. The vocabulary is used in order to get the meaning of words in gaining the meaning of a dialogue happened in the film.

a. Subtitles

Subtitle is textual versions of the dialogue in film and television programs, usually displayed of the bottom of the screen. According to Lever H.J, there are two types of subtitles, integralingual and interlingual subtitling. Intralingual subtitling deals with the production of subtitles that remain in same language as the original and are used for the deaf or hard of hearing, or for language learners. On the other hand, interlingual subtitling refers to both a change in mode and language and form spoken dialogue into a written, condensed translation which appears on the screen.

Interlingual subtitle is the types of subtitle used in this research. According to Danan (2004) audiovisual material enhanced with captions or interlingual subtitles is a particular powerful pedagogical which can help improve the listening comprehension skill of second language learners. Subtitling is helping the students visualize what they hear, especially if the input is not too far beyond their linguistics ability. Subtitling can also increase language comprehension and leads to additional cognitive benefits, such as greater depth of processing.

In subtitle expected to make the students easier to understand the meaning of the dialogue in film, since the students have to rewrite the story 
in film, the subtitle is one of the helpful tools for the students to grapes the meaning of the dialogue in film. The subtitle of the film is Indonesia language form.

b. The story in film

The story in film is a story in narrative structure form. Around the turn of the twentieth century, films began developing a narrative structure by stringing scenes together to tell narratives. It means in order to understand the story in the film; students have to know the narrative and the structure of narrative.

Narrative structure is the form of story. The common features of narrative structure are beginning /orientation, problem/complication problem is solved/ending, resolution, and moral/coda/evaluative ending (Figg, 2006).

In the beginning/orientation there is set of the scene, creating a visual picture of the setting, atmosphere and time of the story, and also introduction of characters and clues set in place for the coming complication. The problem/complication is the phase where a problem and complication occurs that affects the setting, time, or characters. In the problem seems to be resolved/minor resolution, everything seems to be resolved. The new problem/complication shows that the problem or complication now often worse than before. After that problem is solved/ending/resolution phase shows that the problem is solved and the story ends. In the end, there is moral/coda/evaluative ending, shich shows whether there is moral or message at the end of story (Figg, 2006).

\section{METHODOLOGY}

In this research, the research used descriptive design. Descriptive research is method that tries for describe object based on reality (Best, 1982:119). The technique use in this research is correlation analysis technique. This technique is used to find out the correlation degree between the independent variable (student rewriting of the story) and the dependent (vocabulary mastery). The sampling technique used cluster sampling, which collects the sample randomly in a 
population. The sample of this study was 28 students of eighth grade students of SMP HANDAYANI Sungguminasa Gowa. This test used to find out students rewriting of the story in film test. The test will be conducted by asking the students to rewrite the story in film, which titled is UP animation movie. There will be two criteria to be scored, they are content and vocabulary. Which adapted from Brown (1994: 356 - 358) and Klara (2007).

The data collecting procedure of this study was based on test. There were two variables analyzed. Namely student's rewriting of the story in film (independent variable) and vocabulary mastery (dependent variable). Student's rewriting of the story in film (independent variable). Student's rewriting of the story in film means their writing activity in retelling story in the film. The film used in this research, which titled UP, is a film with subtitle that is suitable for Junior high school level. Student's vocabulary mastery (independent variable). Student's vocabulary mastery here means the number of vocabulary that student know from the film shown. To measure student's vocabulary mastery they will be given a number of questions based on the vocabulary in film.

\section{FINDINGS}

\section{Students' Writing Ability}

After doing the research, it was found the description about the students' writing ability through their test score, the result of vocabulary mastery test found that the students have fair competence of their writing ability (in terms of rewriting of the story in film), it was showed by the result of mean score analysis namely 6,00.

\section{Students' Vocabulary Mastery}

The description of students' vocabulary mastery was found by vocabulary test, it was point out that mean score of students' vocabulary was 61,0 it classified as poor score.

\section{Correlation between the Students' Writing Ability and Their Vocabulary Mastery.}


The result of the correlation analysis between students' writing ability (in terms of rewriting of the story in film) and students' vocabulary mastery shows that those are at the substantial level and have correlation.

The rxy score is 0,696 which is greater than $r$ table score 0,413 . The research concludes that the students' writing ability (in terms of rewriting of the story in film) and their vocabulary mastery of the eighth grade students of SMP Handayani Sungguminasa Gowa have significant correlation with their writing skill. The position of the significant correlation is substantial which lies between $0,600-0,800$.

The result of this research shows that film can be one of media in learning English. Students did not only have good score in rewriting of the story in film test but also vocabulary mastery test, this mean that film can help the students improve their writing ability and to create interesting atmosphere in learning the vocabulary occur in the film as indicated in this research.

It is in accordance with the previous researchers which were found by febrianti fajrah that there is a significant correlation between watching movie and students' vocabulary. On the other side, the research finding of saparuddin found that Improving students' Vocabulary through watching animation movie.

By considering the previous research finding and the findings of this research itself, the writer states that the students writing ability (in terms of rewriting of the story in film) it has close relation with communication skills in English, namely listening, speaking, reading, especially in sub skill is vocabulary mastery.

\section{CONCLUSIONS}

The lack use of media become a problem in learning English as a foreign language as indicated in this research. Basically, students' interest in learning English can be increased by providing interesting media in teaching English. As Stempleski (1990:3) stated, the help of moving picture and sounds build the 
interest. The finding of this research, the writer concluded that there is a significant correlation between students' writing ability (in terms of rewriting of the story in film) and their vocabulary mastery. Since the two variables correlates significantly, the position of their significant is substantial which lies between 0,600-0,800. It shows that the students' writing ability (in terms of rewriting of the story in film) can increase or has effect of their vocabulary mastery.

\section{REFERENCES}

Astuti.2005. Teaching Vocabulary at the Eighth Grade Students of SMP Negeri 2 Bontonompo by Using Funny Stories. Thesis FBS UNM.

Burton, S. H. Mastering English Language, London: The Macmillan Press Ltd, 1982

Byrne Donn.1988.Teaching Writing Skills, Hongkong: Longman Group (FE) Ltd. Champoux, Joseph E. 2007. Film as a Teaching Resource.Retrieved from http:/mgtclass.mgt.unm.edu/champoux.pdf.

Danan M.2004. Captioning and Subtitling:Undervalued Language Learning Strategis.[online]. Available at:

http://www.erudit.org/reveve/meta/2004/v49/n1/009021.ar.html.

Devi ika.2012 “Animation Video to Improve Students' Vocabulary Mastery”.

Journal of English Education

Ermayanti, Dewi.2006. The Correlation between Students' Vocabulary Mastery and Their Reading Comprehension Score in TEOIC. Universitas Negeri Makassar

Fajrah Febrianti.2008.The correlation between watching movie and students' vocabulary mastery. Universitas Negeri Makassar.

Farhady, Hossein \& Evelyn Hatch. 1982. Research Design and Statistics for Applied Linguistics.Newburry House Publishers, Inc. Rowley, Massachusetts.

Figg S, 2006. Understanding Narrative Writing: Practical Strategies to Support Teachers.

Gairns Ruth and Redman Stuart.1986.Working with Words, New York: Cambridge University Press Geddes M. \& Sturtridge G.1982, "Video in the 
Language Classroom." Practical Language Teaching. Heineman Educational Books.

Ismayanti.2008. The Effectiveness of Teaching Vocabulary Through Audiovisual Material in Second Grade Students of SMPN 6 Bandung. University Pendidikan Indonesia.

Kim, Miyoun (Sophia). 2006. Genre-Based Approach to Teaching Writing (online). Available at:

http://web1.hpu.edu/images/GraduateStudies/TESL_WPS/07Kim_Genre_al7238. pdf.

Langan, John. College writing skill with Reading.USA: McGraw-Hill, inc, 1993.

Lever H.J. (no date). MA Translation \& Interpreting.[online]. Available at: http://www.peak-translationco.uk/chapter two-subtitling.doc.

Linda .2004. Using Audiovisual Material in Teaching English at the Eighth Grade Students of SMP Negeri 2 Majene. Thesis FBS UNM.

Mahbubah, Sitti (2005). The Use of Word Attack in Developing Vocabulary Mastering to the Second Year Students of Aliyah Bulu Lampang DDI Mangkoso Barru. Thesis UIN Alauddin.

Mantasiah.2001. Learning English Vocabulary by Using Authentic Materials can Increase the Students' Vocabulary. Thesis FBS UNM

McCarthy, Michael, and Felicity O’Dell. English Vocabulary in Use Opper intermediate and advanced. England: University press, 1994.

Richards, Jack C. Curriculum Development in Language Teaching. United Kingdom: Cambridge University Press, 2002.

Setiawandi D. 2006. The effectiveness of conversations and pictures in improving Students' Vocabulary Mastery. Universitas Negeri Makassar.

Sugiyono, Prof. Dr. 2007.Metode Penelitian Pendidikan Pendekatan Kuantitatif, Kualtatif, dan R\&D. Alfabeta.

Supriyanti Wiwin . 2008. The effectiveness of Fairytale Movie as a Medium in Teaching Narrative Writing at the eleventh grade students of SMAN8 Makassar. Thesis FBS UNM 
Surmita.2010.The correlation between students' grammar ability and their writing skill.Universitas Muhammadiah Makassar.

Wallace.1989.Teaching Vocabulary ELBS. New York Oxford University press Inc.

Watson Robert. 1990. Film and Television in Education: An Aesthetic Approach to the Moving Image. The falmer press. 